\title{
A prospective observational study conducted in tertiary teaching hospital of Uttar Pradesh to compare safety and efficacy of PPIUCD and interval IUCD (380A)
}

\author{
Nidhi Gupta*, Akanksha
}

Department of Obstetrics and Gynecology, S.N. Medical College, Agra, Uttar Pradesh, India

Received: 24 August 2018

Accepted: 06 December 2018

*Correspondence:

Dr. Nidhi Gupta,

E-mail: dr.nidhi_gupta@rediffmail.com

Copyright: () the author(s), publisher and licensee Medip Academy. This is an open-access article distributed under the terms of the Creative Commons Attribution Non-Commercial License, which permits unrestricted non-commercial use, distribution, and reproduction in any medium, provided the original work is properly cited.

\begin{abstract}
Background: The objective of this study was to compare the efficacy and safety of PPIUCD and interval IUCD.

Methods: This was a prospective observational study conducted on women attending the OPD and indoor services of S.N. Medical college, Agra. 800 women willing for PPIUCD insertion were included in the study after informed consent excluding chorioamnionitis, PROM>18 hours, unresolved PPH and puerperal sepsis. Another 200 willing women were inserted interval IUCD according to MEC criteria of WHO. All were followed up for 1 year.

Results: It was found that rate of expulsion was more in PPIUCD group compared to interval IUCD group (6\%vs $1.5 \% \mathrm{p}$ value <.05), rate of removal was almost similar in both groups (11.5\% inPPIUCD and 14\% in interval IUCD group), cause of removal was mainly social in PPIUCD group while bleeding was more in interval IUCD group compared to PPIUCD $(85.7 \%$ vs $26 \%)$.
\end{abstract}

Conclusions: Postpartum insertion of IUCD is a safe effective, feasible and reversible method of contraception.

Keywords: Acceptance, Interval IUCD, PPIUCD, Safety

\section{INTRODUCTION}

Using family planning to space births at least 36 months apart can avert $30 \%$ of maternal deaths and $10 \%$ of child deaths. $^{1,2}$ In India, however only $26 \%$ of postpartum women are using contraception and more than $60 \%$ of birth follow an interval of less than 36 month. ${ }^{3,4}$ Sterilization has remained the leading method of contraception in India accounting for $40 \%$ of family planning users and but it does not address women's needs for healthy birth spacing. PPIUCD is a long acting, reversible contraceptive offering a safe, effective and convenient alternative to sterilization. It has also been found acceptable among Indian women as rate of motivation is more in post-partum period. In the last decade more and more women chose to give birth in health institutions because of Janani Suraksha Yojana. This gives a unique opportunity to offer a long acting yet reversible method of contraception to women immediately after child birth. Delaying until later is not effective as most of clients do not return for family planning services. It is advantageous as it is free of cost. Insertion of an IUD after delivery may avoid the discomfort related to interval insertion, and any bleeding from insertion will be disguised by lochia. The benefit of PPIUCD is that woman is known to be non-pregnant, and her motivation for contraception is high. For women with limited access to medical care, delivery offers an unique opportunity to address need for contraception, considering this fact; the mentioned study was conducted to evaluate the safety and efficacy of PPIUCD versus interval IUCD (380A). 
And to evaluate the safety and efficacy of PPIUCD compared to interval IUCD in terms of safety, acceptance and complication like bleeding, infection and expulsion.

\section{METHODS}

This study was a prospective observational study conducted on women attending the OPD and indoor services in the department of obstetrics and Gynecology of S.N. Medical college, Agra, from April 2017to April 2018. A total of 1000 women were included in the study and divided into two groups. Study group consisted of total 800 women of immediate post-partum, 400 were of normal delivery and 400 were trans caesarian. Control group included 200 women who were willing for interval insertion of $\mathrm{Cu}$ T380A after informed choice according to MEC criteria laid down by WHO.

\section{Inclusion criteria}

- Patients who had institutional deliveries and desire to use CuT380A for contraception and willing to sign an informed consent with age $>18$ years and are ready to be in regular follow up were included in the study.

\section{Exclusion criteria}

- Patients who had unresolved PPH, PROM>18hrs, signs of chorioamnionitis, puperal sepsis or age $<18$ or $>45$ were not included in study.

Informed and written consent was taken after which IUCD (Copper T 380A) was inserted immediately after delivery of placenta by using Kelly's forceps in vaginal delivery and by using sponge holding forceps in caesarian delivery before closure of uterine incision. These cases were followed at 15 days, 6 weeks, 6 months and 1 year. Results were compared with interval IUCDs.

\section{RESULTS}

Total deliveries conducted in duration of present study was 2500.Total acceptance rate of PPIUCD in present study was $32 \%$ and majority of cases who accepted PPIUCD belonged to age group of 20-25years (Table 1).
Table 1: Acceptance rate of PPIUCD in different age groups.

\begin{tabular}{|l|l|l|l|}
\hline Age group & Total no deliveries & $\begin{array}{l}\text { No. of } \\
\text { accepted }\end{array}$ & $\%$ \\
\hline$<20$ & 42 & 2 & 4.7 \\
\hline $20-25$ & 1390 & 520 & 37.4 \\
\hline $26-30$ & 897 & 256 & 28.5 \\
\hline $30-35$ & 106 & 20 & 18.8 \\
\hline$>35$ & 65 & 2 & 3 \\
\hline Total & 2500 & 800 & 32 \\
\hline
\end{tabular}

Expulsion occurred in 48cases $(6 \%)$ after immediate PPIUCD of which $38(9.5 \%)$ occurred after normal vaginal delivery which was significantly higher than in trans cesarean group $10(2.5 \%)$. Total 3(1.5\%) expulsion occurred in the interval IUCD group (Table 2).

Table 2: Comparison of expulsion in three groups.

\begin{tabular}{|l|l|l|l|}
\hline & Expulsion rate & $\%$ & P value \\
\hline Vaginal delivery (200) & 38 & 9.5 & $<0.04$ \\
\hline LSCS (200) & 10 & 2.5 & $>0.04$ \\
\hline Interval (100) & 3 & 1.5 & $>0.04$ \\
\hline
\end{tabular}

IUCD were removed in total 92cases (11.5\%) after postpartum insertion, of which 44 were cases with normal delivery and 48 were with Tran's caesarean, almost equal in both groups. In interval group IUCD was removed in only $28(14 \%)$ cases. More than $85 \%$ women continued the IUCD in both the groups (Table 3 ).

Table 3: Continuation rate after one year were comparable in 3 groups.

\begin{tabular}{|l|l|l|l|}
\hline & $\begin{array}{l}\text { No. in each } \\
\text { group }\end{array}$ & $\begin{array}{l}\text { No. who } \\
\text { continued }\end{array}$ & $\begin{array}{l}\text { Who } \\
\text { continued }\end{array}$ \\
\hline After ND & 400 & 356 & $89 \%$ \\
\hline Transcesarean & 400 & 352 & $88 \%$ \\
\hline Interval & 200 & 172 & $86 \%$ \\
\hline
\end{tabular}

Complication occurred in $20.25 \%$ (162) cases after PPIUCD (74 in normal vaginal group and 88 trans caesarean group), while after interval insertion complication occurred in $25 \%$ (50) cases.

Table 4: Complication after IUCD insertion in 3 groups.

\begin{tabular}{|c|c|c|c|c|c|c|}
\hline & \multicolumn{2}{|c|}{ Vaginal delivery } & \multicolumn{2}{|c|}{ Trans cesarean } & \multicolumn{2}{|c|}{ Interval } \\
\hline & No. & $\%$ & No. & $\%$ & No. & $\%$ \\
\hline Bleeding & 14 & 3.5 & 18 & 4.5 & 16 & 8 \\
\hline Discharge & 10 & 2.5 & 20 & 5 & 10 & 5 \\
\hline Pain & 10 & 2.5 & 10 & 2.5 & 4 & 2 \\
\hline PID & 0 & 0 & 0 & 0 & 2 & 1 \\
\hline Missing thread & 2 & 0.5 & 30 & 7.5 & 0 & 0 \\
\hline Expulsion & 38 & 9.5 & 10 & 2.5 & 3 & 1.5 \\
\hline Total & 74 & 18.5 & 88 & 22 & 50 & 25 \\
\hline
\end{tabular}


Table 5: Cause of removal in 3 groups.

\begin{tabular}{|l|l|l|l|l|l|l|}
\hline & Vaginal delivery & Trans cesarean & \multicolumn{2}{c|}{ Interval } \\
\hline So. & $\mathbf{\%}$ & No. & $\mathbf{\%}$ & No. & \multicolumn{1}{c|}{} \\
\hline Bleedial & 34 & 77.2 & 26 & 54.1 & 0 & 0 \\
\hline Discharge & 6 & 13.6 & 18 & 37.5 & 24 & 85.7 \\
\hline Pain PID & 0 & 0 & 0 & 0 & 0 & 0 \\
\hline Wants Conception & 0 & 0 & 0 & 0 & 4 & 14.2 \\
\hline Other contraceptive methods & 4 & 9.2 & 2 & 4.1 & 0 & 0 \\
\hline Total & 0 & 0 & 2 & 4.1 & 0 & 0 \\
\hline
\end{tabular}

Most common complication after PPIUCD insertion was expulsion while after interval insertion bleeding was most common complication (Table 4).

Cause of removal was mainly bleeding $85.7 \%$ (12) cases in interval IUCD group which was more than in PPIUD group (26\%) (24). In PPIUCD group the IUCD was mostly removed because of social reasons65.2\% (60) cases (Table 5).

\section{DISCUSSION}

PPIUCD is a highly effective, long acting, reversible, cost effective and easily accessible family planning method that is safe for use by most postpartum women including those who are breast feeding. ${ }^{5}$

Total acceptance rate of PPIUCD in present study was $32 \%$.Majority of the cases who accepted PPIUCD belonged to the age group $20-25$ years $(37.4 \%)$ this was probably because most of the patients who come to the hospital for delivery also belong to age group 20-25 years. This is in accordance to study of Katheit $G$ et al $2013 .^{6}$

The results of present study showed that expulsion rates after vaginal PPIUCD were $9.5 \%$ which is in accordance with study of Haynes JL et al $2007 .^{2}$ In the present study expulsion after transcaesarean insertion occurred in $2.5 \% \%$ cases, which is comparable with the results of study of Muller ALL et al, Lopez-Farfan JA et al. ${ }^{7,8}$ According to present study rate of expulsion of PPIUCD was significantly higher in the normal vaginal delivery group $(9.5 \%)$ than in transcaesarean group $(3 \%)$. The lower expulsion rate after transcaesarean insertion as compared to vaginal insertion may be due to direct placement of IUD at the fundus during caesarean section.

The rate of expulsion in interval IUCD group in present study was $1.5 \%$ which was significantly lower $(\mathrm{p}<0.05)$ as compared to PPIUCD group (6\%). Expulsion rates were comparable between transcaesarean and interval IUCD group; i.e. $3.5 \%$ and $1.5 \%$ respectively. Bonilla Rosales F et al in their study found expulsion rate of $16 \%$ and $2 \%$ for PPIUCD and interval IUCD respectively. ${ }^{9}$ The cumulative rate of removal over 1year follow up after PPIUCD insertion was $11.5 \%$, almost equal in both vaginal delivery and transcaesarean group (11\% and $12 \%$ respectively). In present study, rate of removal in interval insertion group was $14 \%$ (28 cases), whereas it was $11.5 \%$ (92 cases) in PPIUCD group. In present study various complications were seen in 162 cases $(20.25 \% \%)$ in those who chose immediate postpartum insertion. Expulsion was the most common complication in the vaginal group $(9.5 \%)$ while in the transcaesarean group missing thread $7.5 \% \%$ (30 cases) was the most frequent complication. Bleeding occurred in $32(4 \%)$ cases, 14 cases $(3.5 \%)$ of bleeding were reported from vaginal delivery group and in the transcaesarean group bleeding occurred in 18cases (4.5\%). Celen $\mathrm{S}$ et al reported cumulative rates of bleeding equal to $11.4 \%$ and $8.2 \%$ respectively. No case of PID/endometritis reported in present study. ${ }^{10}$ EL Beltagy et al also reported no increase in the incidence of PID after immediate postpartum IUCD insertion. ${ }^{11}$ No case of perforation was reported from both the groups. This decreased risk of uterine perforation may be because of thick wall of the uterus. This is in accordance with the study of El Shafei MM et al and Ricalde et al where no perforations were observed in PPIUCD. No failure reported from both the groups. ${ }^{12,13}$

While comparing PPIUCD with interval IUCD the cumulative rate of complications in present study were $20.5 \%$ and $25 \%$ in PPIUCD group and interval IUCD group respectively). This was in accordance with the study Eroglu et al where the rates of complications did not differ significantly between the two groups. ${ }^{14}$

Present study showed continuation rates of about $88.5 \%$ for PPIUCD users over a follow up period of 1 year. Celen et al also showed continuation rates of $87.6 \%$ for PPIUCD at 6 months interval. ${ }^{10}$ On comparing the interval IUCD with PPIUCD, slightly lower continuation rates were obtained for Interval IUCD group (86\%) than PPIUCD group $(88.5 \%)$ in present study. Although slight difference exists between the two groups, but the difference was not statistically significant $(\mathrm{p}=.49)$.

\section{CONCLUSION}

From the above study we came to the conclusion that postpartum insertion of PPIUCD is safe effective, 
feasible and reversible method of contraception. Compared with interval insertions, postpartum insertions do not increase the risk of infection, endometritis, bleeding, uterine perforation. Nor do they affect the return of uterus to normal size. Particularly noteworthy is the very low rates of perforation in the postpartum period because of the thickened uterine walls. IUCDs if safely inserted in immediate postpartum period and included as a part of obstetrical management of the patient, contraceptive protection can be provided for the high-risk group of obstetrical patients which need but wouldn't take advantage of available contraceptive services at any other time.

Funding: No funding sources

Conflict of interest: None declared

Ethical approval: The study was approved by the Institutional Ethics Committee

\section{REFERENCES}

1. World Health Organization (WHO) Report of a technical consultation on birth spacing. Geneva Switzerland. .World Health Organization (WHO) (2005)

2. Hayes JL, Cwiak C, Goedken P, Zieman M. A pilot clinical trial of ultrasound-guided postplacental insertion of a 1 evonorgestrel intrauterine device. Contracep. 2007;76(4):292-6.

3. National Family Health Survey (NFHS-3) 2005-06 IIPS(International Institute for Population Sciences) Mumbai; India (2007)

4. World Health Organization (WHO) Programing stratigies for post - partum family planning. WHO Geneva C (2013).

5. Gupta A, Verma A, Chauhan J. Evaluation of PPIUCD versus interval IUCD (380A) insertion in a teaching hospital of Western U. P. Int J Reprod Contracept Obstet Gynecol. 2013;2(2):204-8.

6. Katheit G, Agarwal J. Evaluation of post-placental intrauterine device (PPIUCD) in terms of awareness, acceptance, and expulsion in a tertiary care centre. Int J Reprod Contracept Obstet Gynecol. 2013;2(4):539-43.

7. Mülller ALL, Ramos JGL, Martins-Costa SH, et al. Transvaginal ultrasonographic assessment of the expulsion rate of intrauterine devices inserted in the immediate postpartum period: a pilot study. Contracep. 2005;72(3):192-5.

8. López-Farfan J, Martinez MM, Machorro IV. P729 Application of Mirena ${ }^{\circledR}$ during caesarean section (CS). Int J Gynecol Obstet. 2009;107(S2).

9. Bonilla Rosales F, Aguilar Zamudio ME, Cazares Montero ML, Hernandez Ortiz ME, Luna Ruiz MA. Factors for expulsion of intrauterine device TCu380A applied immediately postpartum and after a delayed period. Rev Méd Inst Mex Seguro Soc. 2005;43(1):5-10.

10. Celen S, Möröy P, Sucak A, Aktulay A, Danişman $\mathrm{N}$. Clinical outcomes of early postplacental insertion of intrauterine contraceptive devices. Contracep. 2004;69(4):279-82.

11. El Beltagy NS, Darwish EA, Kasem MS, Hefila NM. Comparison between Cupper T380 IUD and Multiload 375 IUD in early post-partum insertion. Middle East Fertility Society J. 2011;16(2):143-8.

12. El-Shafei MM, Mashali A, Hassan EO, El-Boghdadi L, El-Lakkany N. Postpartum and postabortion intrauterine device insertion unmet needs of safe reproductive health: three years' experience of Mansoura University Hospital. Egyptian Society Obstet Gynecol. 2000;26(1-3):253-62.

13. Ricalde RL, Tobías GM, Pérez CR, Ramirez NV. A randomized comparative study between the $\mathrm{Cu} 375$ and TCu 380A Multiload intrauterine devices placed during the postpartum period. Gynecol Obstet Mex 2006;74:306-11

14. Eroğlu K, Akkuzu G, Vural G, Dilbaz B, Akın A, Taşkın L, et al. Comparison of efficacy and complications of IUD insertion in immediate postplacental/early postpartum period with interval period: 1-year follow-up. Contracept. 2006;74(5):376-81.

Cite this article as: Gupta N, Akanksha. A prospective observational study conducted in tertiary teaching hospital of Uttar Pradesh to compare safety and efficacy of PPIUCD and interval IUCD (380A). Int J Reprod Contracept Obstet Gynecol 2019;8:2958. 